\title{
Bulletin
}

\section{of the Americtall}

Meteorolongical

Socifily

Volume 57 Number 10 October 1976

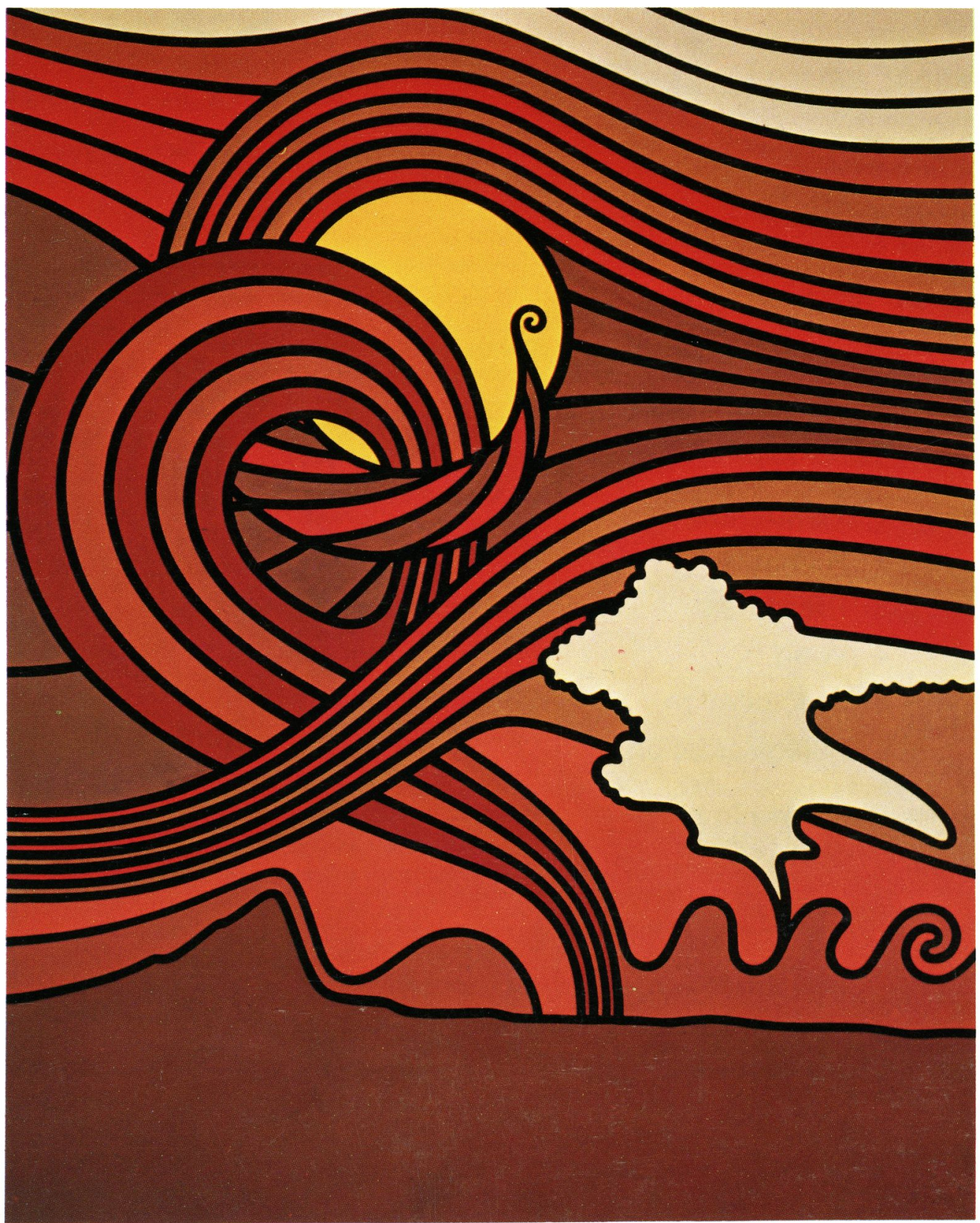




\section{ARE YOU ENERGY-ORIENTED?}

If you're looking for answers-in the wind, sun, or water-we can help you select instruments that will meet your technical specifications and your budget.

Write for our revised literature. Many sections-all part of Catg. No. 9- have been completed.

Sect. 1 Temperature

2 Humidity

3 Pressure

4 Wind

5 Precipitation

6 Solar Radiation

More sections are in preparation.

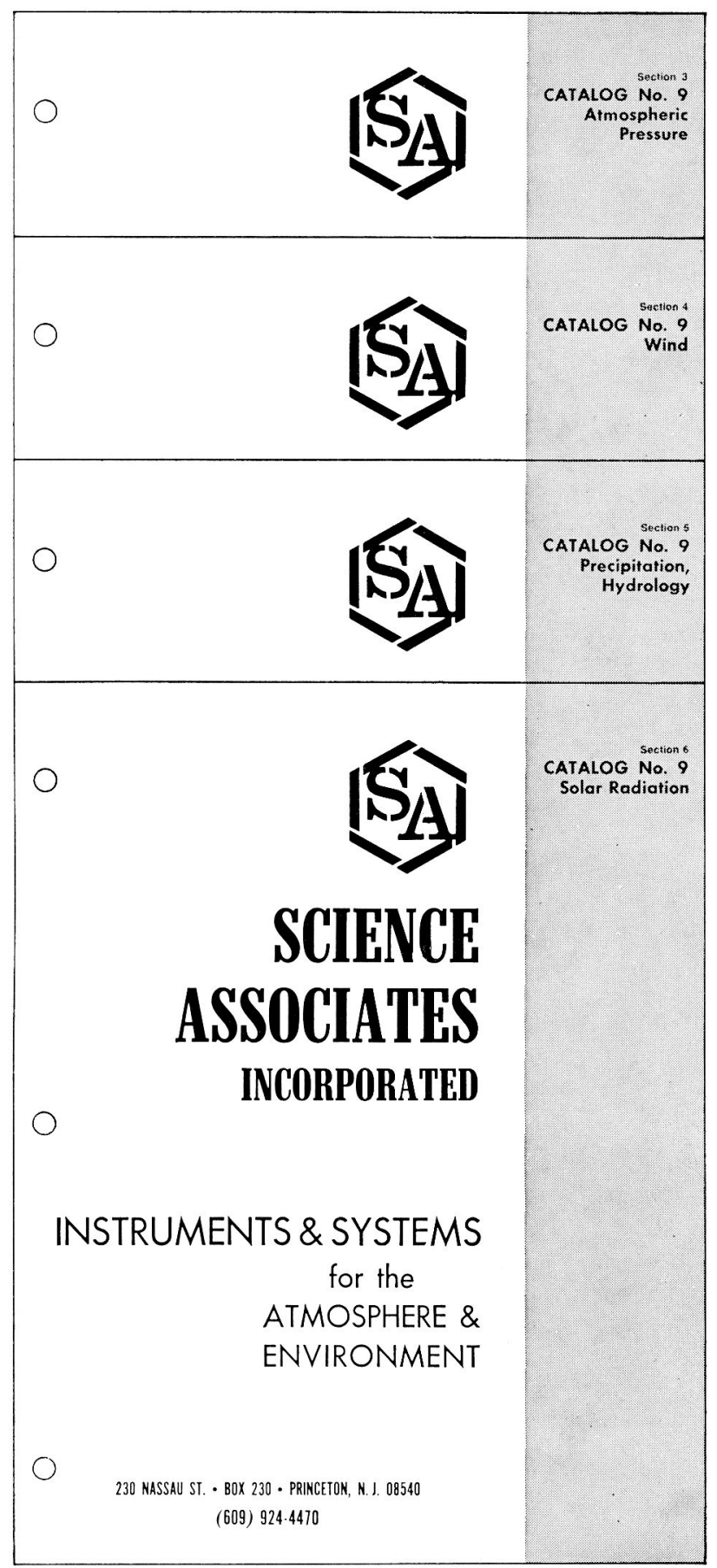




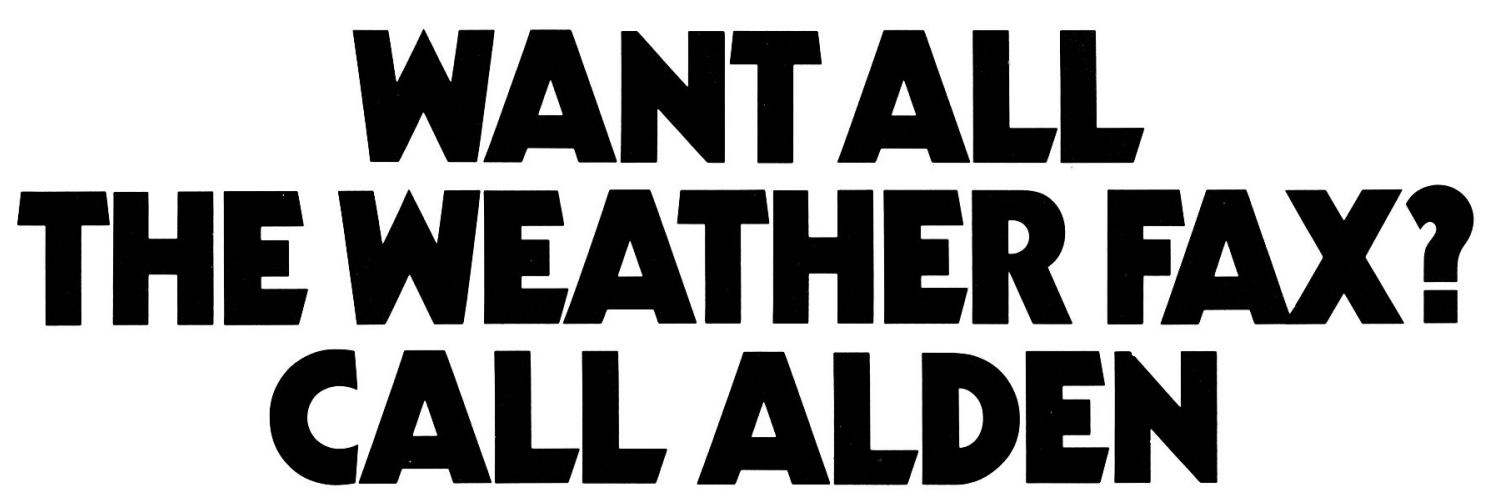

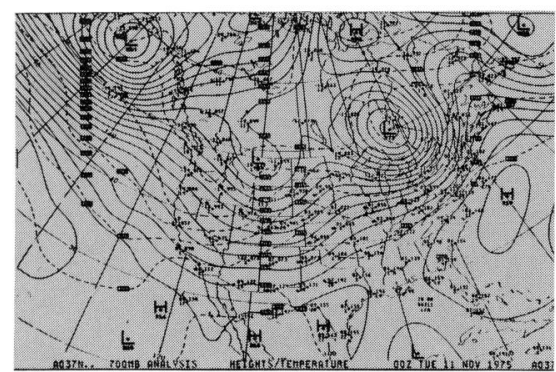

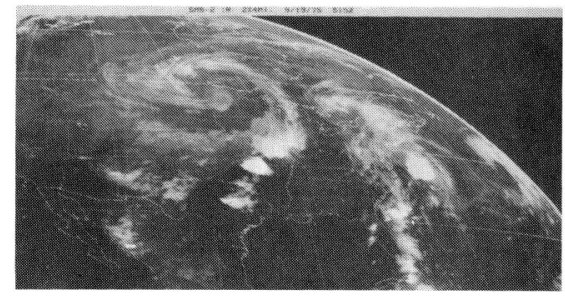

WEATHER CHARTS - With an ALDEN $18^{\prime \prime}$ Recorder you automatically receive high resolution weather charts and faithful reproductions of satellite mosaics over the FOFAX, NAFAX or NAMFAX Networks. ALDEN facsimile recorders are rugged and designed for dependable service - whether used in land or marine environments. Several models are available to suit user requirements for network or radio weather chart reception.

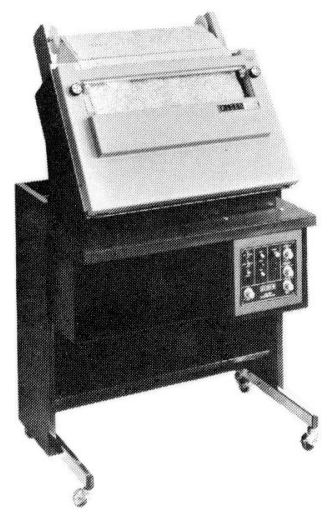

Data Is Recorded Instantly, Permanently - Picture and chart signals are recorded instantly and permanently at the same rate they are transmitted. No processing of charts or pictures is required. Recordings are clean and odor free. No interleaving is necessary. On Alfax electrosensitive paper, where electricity is the ink, recording is not only more simple and direct, but also better suited for easier visual interpretation because of its warm, rich tone shades - where $90 \%$ of the most meaningful cloud information is found. And Alfax paper has unlimited storage life.
NETWORK SATELLITE PICTURES $-\bar{x}$ Recorders are specifically designed to operate on the FOFAX Network which provides an increase in delivery speed and automatic speed selection. Both recorders incorporate the latest electronic circuitry, including solid state replaceable printed circuit cards. The FOFAX Network is available on three separate circuits to provide you with surface analysis, 200/300/500/700/850 MG analysis progs, GOES sectors, long range $3-5$ day forecasts, computer mosaics from orbiting satellites, oceano graphic forecasts $(24 / 36$ hour progs of wind/ wave/swell combined sea

height), aviation forecasts.

Use of the ALDEN MOMSS (Mode and Mes. sage Selection System) allows FOFAX circuit users to program their chart reception by digitized chart number rather than time clock. The ALDEN 1100 and 1800 FOFAX

\begin{tabular}{|c|c|c|c|}
\hline & & \multicolumn{2}{|c|}{$\begin{array}{l}\text { ELECTRONIC \& IMPULSE RECORDING EQUIPMENT CO., INC. } \\
\qquad|| \text { Washington St., Westboro, Ma 01581 (617) } 366-8851 \\
\text { TELEX } 94-8404\end{array}$} \\
\hline \multicolumn{3}{|c|}{$\begin{array}{l}\square \text { Please send your brochure on } \\
\text { ALDEN Recorders for Advanced } \\
\text { Facsimile Networks. } \\
\square \text { Call me at once. My telephone } \\
\text { number }\end{array}$} & $\begin{array}{l}\text { Send additional information on } \\
\square 1800 \text { Weather Chart Recorder } \\
\square 1100 \text { Weather Picture/Chart } \\
\text { Recorder and APT System } \\
\square \text { ALDEN Remote Radar Recorder }\end{array}$ \\
\hline \multicolumn{4}{|c|}{ COMPANY } \\
\hline & DRESS & & ZIP \\
\hline
\end{tabular}

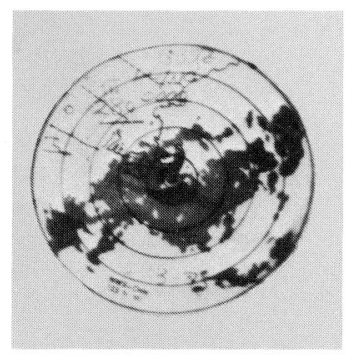

LIVE WEATHER RADAR - With either the ALDEN 600 or ALDEN 1100 WeatheRadar Recorders, you can receive live, realtime weather radar pictures of approaching

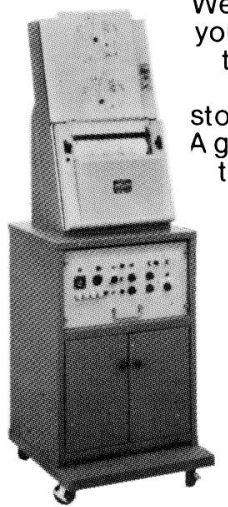
storms or weather fronts. A geographical overlay of the area covered by the radar, radar range marks and any applicable radar meteorologist annotations are transmitted simultaneously with the precipitation echoes. This is accomplished by simply connecting either recorder over the dial up network (using a Data Access Arrangement phone) to any of the NWS radar transmitters. Both recorders can also be connected to a specific radar on a direct line basis.

The ALDEN 1100 Recorder delivers an $11^{\prime \prime}$ picture, the ALDEN 600, a 6 " picture both recorders have automatic and manual framing to properly synchronize the received picture with the radar transmitter. The ALDEN 1100 automat ically prints calendar time/date information on each received radar picture.
Accessory Devices - Paper take-up for hours of unat tended operation - Instrument stand - Tape recorder to back up facsimile recorder or to make extra copies or copy second network.

\begin{tabular}{c}
\hline NATION-WIDE SERVICE \\
Alden offers \\
Nation Wide Service \\
with representatives \\
located in over \\
300 cities in \\
all 50 states.
\end{tabular}




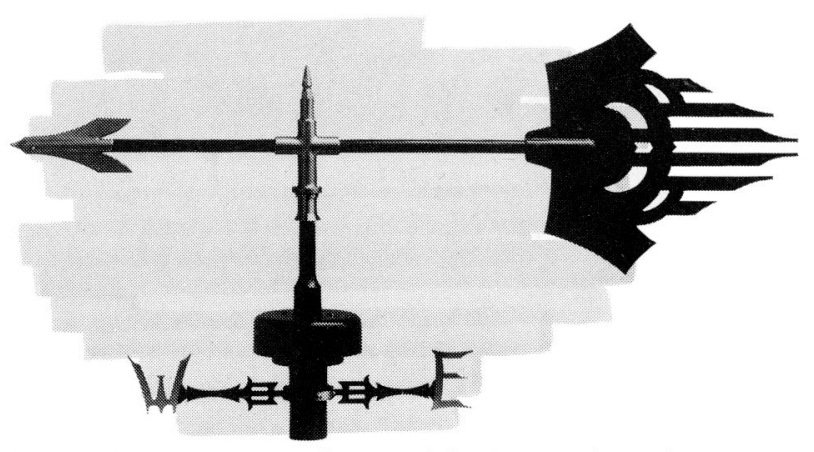

We were gathering precision meteoroFor 100 years, since 1876, we've been telling people what to expect from the world around them. During that time, we've accumulated a wealth of experience and technical expertise on just about everything to do with gauging the environment.

From our meteorological beginnings, we've grown to include instruments and systems for gathering oceanographic data and measuring health and safety criteria required by OSHA. Even new devices to help satisfy stringent EPA regulations and Regulatory Guide 23.

Our products are sensors, indicators, recorders, interfacers, monitors, signal conditioners, automatic scanners, data processors, permanent record keeping instruments. And if you need something special, we'll custom design and build that equipment to meet your needs.

Like to know more about us? Get in contact. We're The Bendix Corporation, Environmental Science Division. You'll find us at 1400 Taylor Avenue, Baltimore, Maryland 21204. Or phone: (301) 825-5200.
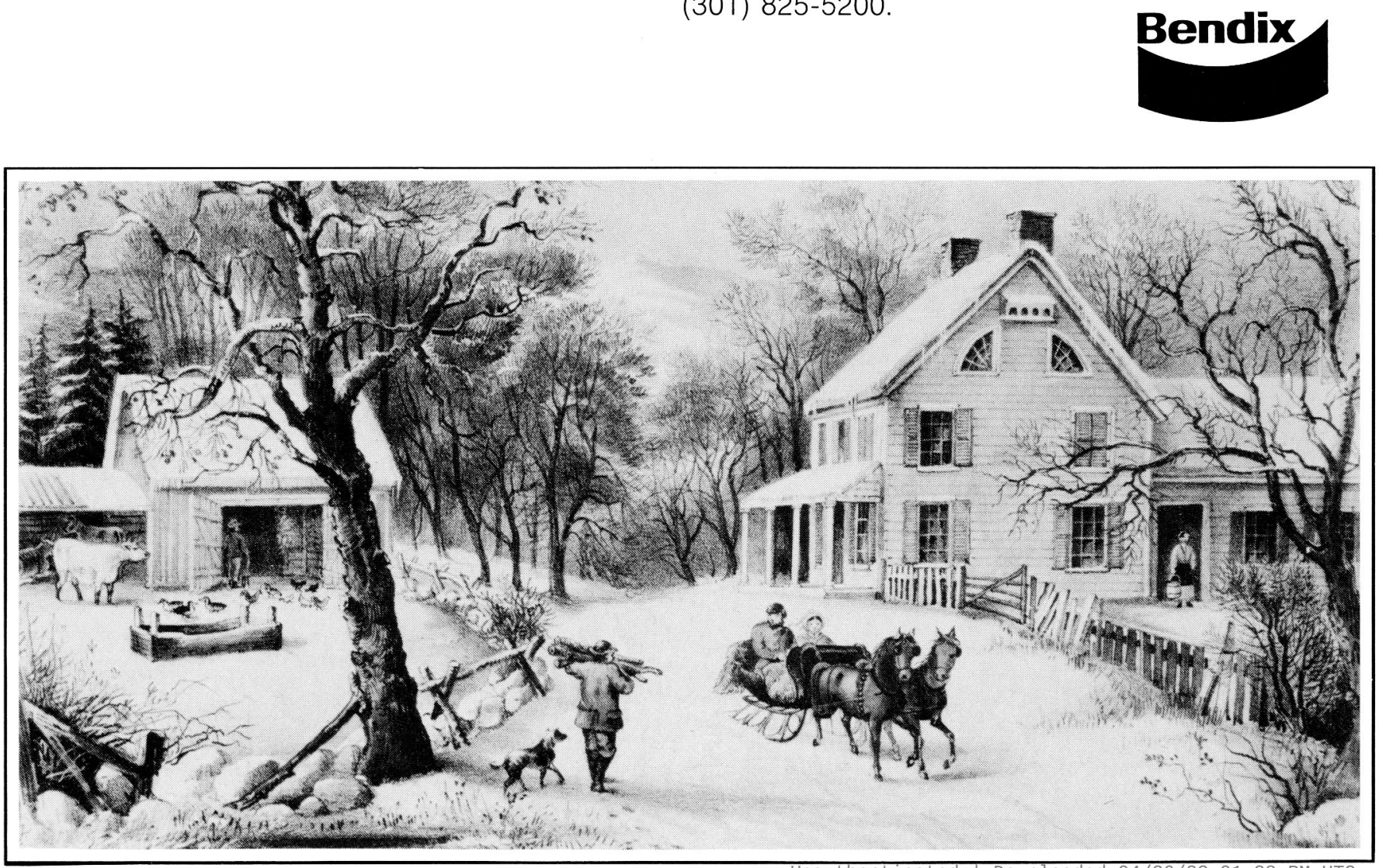

organ of the Society, devoted to editorials, survey articles, professional and membership news, announcements, and Society activities. Editing and publishing are under the direction of Kenneth C. Spengler, Executive Director. Members are encouraged to send to the Society information that they wish to be considered for publication. Four copies of each manuscript (text and illustrations) are required. For guidance on preparation and style, see Information for Contributors on inside covers of a recent issue of any AMS research journal.

AMS Officers and Councilors: President, Charles L. Hosler; PresidentElect, Werner A Baum: Executive Director Kenneth C Spengler: Secretary-Treasurer, David F. Landrigan; Past Presidents, David S. Johnson and David Atlas; and Councilors: Pauline M. Austin, Stanley A. Changnon, Jr., Edward S. Epstein, Neil L. Frank, Francis S. Johnson, Paul W. Kadlec, Albert J. Kaehn, Jr., Roy L. Leep, Jr., Allen D. Pearson, Norman A. Phillips, Robert O. Reid, Joanne Simpson, Joseph Smagorinsky, David K. Todd, Robert M. White.

Published monthly by the American Meteorological Society at 45 Beacon Street, Boston Mass, 02108. Second-class postage paid at Boston, Mass., and at additional mailing offices. Subscription (calendar year only) $\$ 25$ in U.S.; $\$ 30$ outside U.S. Address all business communications, purchase orders, and inquiries regarding the Society to the Executive Director, American Meteorological Society, 45 Beacon Street, Boston, Mass. $02108(617-227-2425)$

Editor Meetings Editor

Kenneth C. Spengler Evelyn Mazur

Technical Editor Assistant Meetings Editor

James E. Caskey, Jr. Twila A. Bombard

News Editor

Advertising

Janet P. Dockery

Lilly G. Albo
Copy Editor

Reine Rosenbaum

volume 57, number 10, October 1976
(C) Copyright 1976 by the American Meteorological Society.

Cover: This design was first used on the cover of the published notes from a scientific colloquium held at NCAR in the summer of 1974 . It was conceived by Dr. Melvyn Shapiro, an NCAR research meteorologist, and was executed by Shapiro and Howard Crosslen, an artist in NCAR's Graphics Group. It has since been painted as a mural on the north wall of the NCAR Mesa Laboratory lobby. The atmospheric themes in the design are interpreted in the correspondence by Shapiro (p. 1243). Among these themes, the atmospheric waves vividly depicted here are particularly relevant to this issue, which includes summaries of the AMS Conferences on Atmospheric and Oceanic Waves and Stability (Hooke et al., p. 1244) and on Ocean-Atmosphere Interactions (Businger, p. 1250).

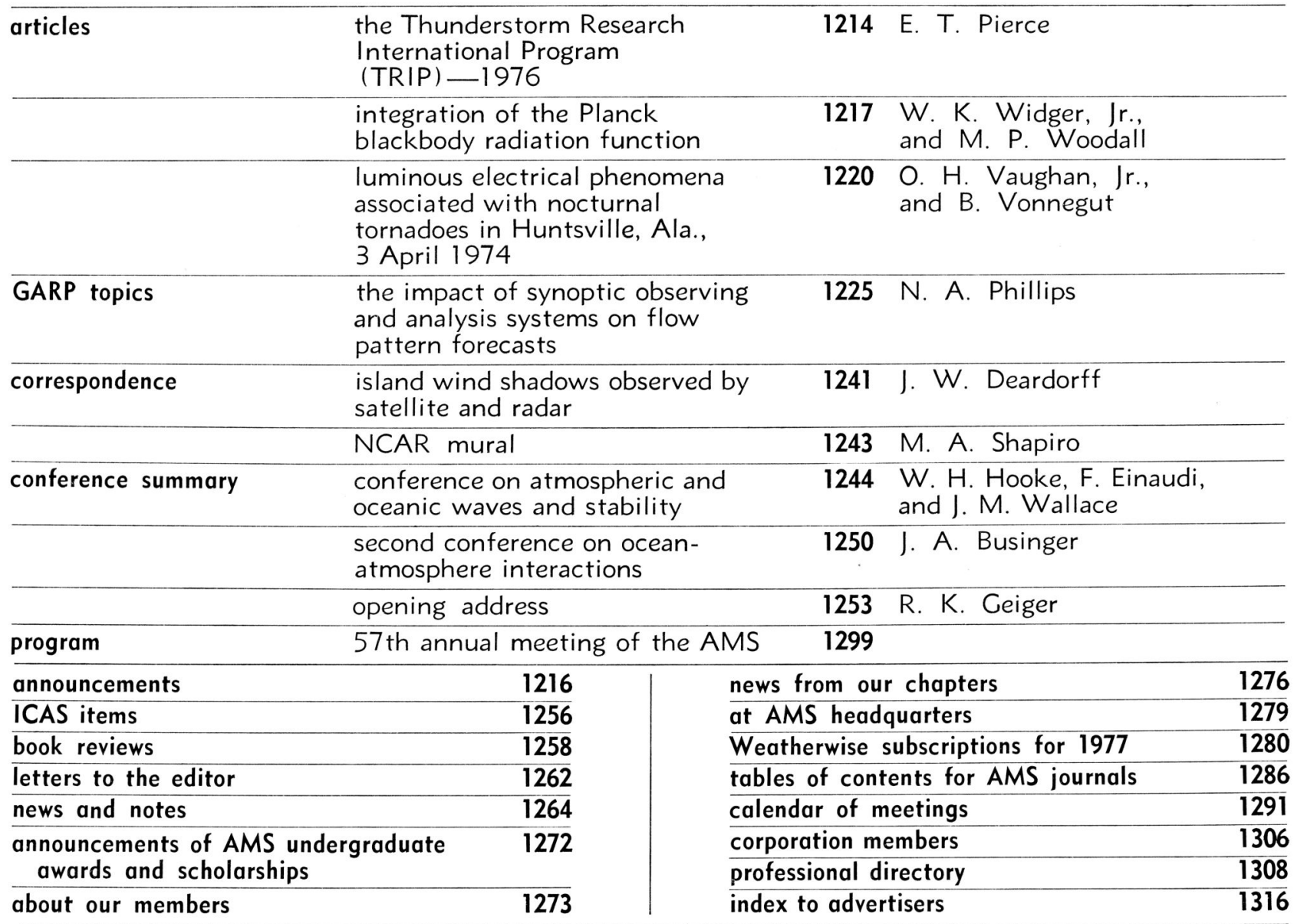

